\title{
Effects of a Hyaluronic Acid/Hydroxypropyl Guar Artificial Tear Solution on Protection, Recovery, and Lubricity in Models of Corneal Epithelium
}

\author{
Rekha Rangarajan, Brian Kraybill, Abayomi Ogundele, and Howard A. Ketelson
}

\begin{abstract}
Purpose: Hydroxypropyl guar (HPG) and hyaluronic acid (HA) have been individually shown to improve dry eye symptoms. The purpose of this in vitro study was to assess the potential benefits of a new lubricant eye drop formulation containing the demulcents propylene glycol and polyethylene glycol and an HA/HPG dual polymer in models of the human corneal epithelium.

Methods: Cultured human corneal epithelial or corneal-limbal epithelial cells were treated with the HA/HPG dual-polymer formulation or single-polymer formulations containing either HPG or HA. Desiccation protection by cell hydration and surface retention was assessed using cell viability assays. Sodium fluorescein permeability, transepithelial resistance, and cell viability assays were conducted using pretreated cells exposed to a surfactant/detergent insult to evaluate cell and cell barrier protection. Surface lubricity was assessed in tribological experiments of pericardium-pericardium friction.

Results: Hydration protection against desiccation and protection by surface retention were significantly greater with the HA/HPG formulation versus HPG or HA $(P<0.001)$ alone and with HPG versus HA $(P \leq 0.016)$. Fluorescein permeability and transepithelial resistance assays demonstrated significantly better cell and barrier protection from surfactant insult with HA/HPG versus the single-polymer formulations $(P \leq 0.01)$. After insult, there were markedly more viable cells evident with HA/HPG compared with HPG or HA alone. HA/HPG and HPG reduced surface friction to a greater extent than HA $(P \leq 0.02)$ and maintained lubricity after the formulations were rinsed away. Conclusions: HA/HPG provided effective hydration and lubrication and demonstrated prolonged retention of effect. HA/HPG may potentially promote desiccation protection and retention on the ocular surface.
\end{abstract}

\section{Introduction}

C HRONIC DRY EYE can lead to desiccation and damage of ocular surface tissues and disrupted epithelial cell barrier function. ${ }^{1,2}$ Instillation of lubricating artificial tears that replenish moisture and decrease friction is a primary approach to dry eye management. ${ }^{3}$ Many artificial tears replace only the aqueous components of the tear film and require frequent administration to maintain efficacy. ${ }^{4}$ Longer-acting formulations are needed that have increased hydration and lubrication effects. ${ }^{5}$

In a randomized double-masked study of dry eye patients with aqueous tear deficiency or noninflammatory meibomian gland disease, artificial tears containing the demulcents propylene glycol and polyethylene glycol demonstrated significantly longer precorneal residence time compared with saline alone, suggesting that these demulcents may prolong the action of dry eye formulations. ${ }^{6}$ Hyaluronic acid (HA) is a naturally occurring viscoelastic hydrophilic polymer that has been shown to reduce ocular surface damage in patients with dry eye, possibly by improving corneal hydration and decreasing surface friction. ${ }^{7}$ Eye drops containing as little as $0.1 \%$ HA increase tear film break-up time and improve symptoms of ocular irritation associated with dry eye. ${ }^{8}$ Drops containing the viscous mucomimetic polymer hydroxypropyl guar (HPG) have also been shown to reduce surface friction ${ }^{5}$ and improve dry eye symptoms. ${ }^{9,10}$ By interacting with lipid components of the tear film, HPG decreases tear evaporation and may increase tear film stability. ${ }^{11}$ Eye drops combining HA and HPG may provide synergistic benefits in enhancing ocular surface hydration and decrease friction to a greater extent than formulations containing a single polymer. 
The purpose of this preclinical study was to assess the potential benefits of a new lubricant eye drop formulation containing the demulcents propylene glycol and polyethylene glycol and a dual polymer, HPG and HA, on hydration, cell and cell barrier protection, and lubricity using in vitro systems modeling the human corneal epithelium.

\section{Methods}

\section{Test formulations}

This in vitro study compared a dual-polymer formulation containing HA, HPG, propylene glycol, and polyethylene glycol (HA/HPG; formulation patent pending by Alcon Research, Ltd., Fort Worth, TX) with similar single-polymer formulations containing either HA or HPG alone. The concentrations of HA and HPG were the same in dual- and single-polymer formulations.

\section{Cell hydration and surface retention}

Monolayer 14-3-3 immortalized human corneal epithelial cells were grown to confluence on collagen IV-coated 48well plates in EpiLife ${ }^{\circledR}$ medium (Life Technologies, Grand Island, NY) supplemented with human corneal growth supplement (Life Technologies). Media were then removed and confluent cells were incubated with $150 \mu \mathrm{L}$ of test formulations, using media as a negative control, for $30 \mathrm{~min}$ at $37^{\circ} \mathrm{C}$. For assessment of cell hydration protection against desiccation, formulations and media were removed after incubation, and cells were desiccated at $37^{\circ} \mathrm{C}$ with $45 \%$ humidity for $30 \mathrm{~min}$. For assessment of desiccation protection by surface retention, test formulations were removed and cells were rinsed 5 times with media before desiccation.

Cell viability was assessed using an MTS assay (CellTiter $96^{\circledR}$ AQueous Non-Radioactive Cell Proliferation Assay; Promega, Madison, WI) according to the manufacturer's instructions. Protection was calculated as percent viability relative to a desiccated media control, normalized to an undesiccated media control $(n \geq 10$ per test solution and condition).

\section{Cell and cell barrier protection}

Cell culture and treatment. Cell and cell barrier protection after exposure to the nonionic detergent Triton ${ }^{\mathrm{TM}}$ X-100 (The Dow Chemical Company, Midland, MI) were assessed by sodium fluorescein permeability, transepithelial electrical resistance, and a live/dead cell viability assay. Immortalized human corneal-limbal epithelial cells were provided by Dr. Ilene Gipson (Schepens Eye Research Institute, Harvard Medical School, Boston, MA). Cells were grown to $50 \%$ confluence in the keratinocyte serum-free medium (K-SFM; Life Technologies) supplemented with bovine pituitary extract, $0.2 \mathrm{ng} / \mathrm{mL}$ epidermal growth factor (EGF), $100 \mathrm{U} / \mathrm{mL}$ penicillin, $100 \mu \mathrm{g} / \mathrm{mL}$ streptomycin, and $0.4 \mathrm{mM} \mathrm{CaCl} 2$. At $50 \%$ confluence, cells were switched to the confluence medium [50\% K-SFM, 25\% low-calcium Dulbecco's modified Eagle's medium (DMEM), and 25\% Ham's F-12 nutrient mixture (F12)] and grown to full confluence. Cells were switched to 12 -well culture inserts and induced to stratify in stratification medium (50\% DMEM and $50 \%$ F12) supplemented with $10 \%$ calf serum, $10 \mathrm{ng} / \mathrm{mL}$ EGF, $100 \mathrm{U} / \mathrm{mL}$ penicillin, and $100 \mu \mathrm{g} / \mathrm{mL}$ strep- tomycin. Stratified cells were grown in 12-well culture inserts containing $0.5 \mathrm{~mL}$ stratification medium per insert and $1.5 \mathrm{~mL}$ per well of the companion 12-well plate, rinsed with Hank's balanced salt solution (HBSS) containing $1.26 \mathrm{mM}$ $\mathrm{CaCl}_{2}$ and $0.49 \mathrm{mM} \mathrm{MgCl}_{2}$ (HBSS Complete; Life Technologies), and incubated with $500 \mu \mathrm{L}$ of test formulations for $30 \mathrm{~min}$ at $37^{\circ} \mathrm{C}$ with $5 \% \mathrm{CO}_{2}$. Formulations were removed without washing, and cells were incubated for $30 \mathrm{~min}$ with $500 \mu \mathrm{L}$ of $0.022 \%$ Triton $\mathrm{X}-100$ in phosphate-buffered saline. For each sample, cell protection was assessed immediately after exposure to Triton X-100 and following a 4 -h recovery in stratification medium at $37^{\circ} \mathrm{C}$. Samples incubated with media instead of test formulations were included as negative controls.

Sodium fluorescein permeability. For sodium fluorescein permeability assessments, cells and inserts were rinsed with HBSS, and $500 \mu \mathrm{L}$ of $0.02 \%$ sodium fluorescein in HBSS Complete without phenol red was added to each insert. Inserts were transferred to new 12 -well plates containing $1.5 \mathrm{~mL} \mathrm{HBSS}$ per well. Cells were incubated at $37^{\circ} \mathrm{C}$ for $30 \mathrm{~min}$, allowing the fluorescein to diffuse through the cultures into the HBSS in the wells below. Inserts were removed from the plates, and $100 \mu \mathrm{L}$ of each sample was transferred in duplicate to a 96-well white-walled plate for analysis using a microplate fluorometer (excitation, $485 \mathrm{~nm}$; emission, $530 \mathrm{~nm}$ ), with fluorescein permeability measured in relative fluorescence units (RFUs). Inserts were returned to the original culture plates, rinsed with HBSS, replenished with stratification medium, and incubated at $37^{\circ} \mathrm{C}$ for $4 \mathrm{~h}$ of recovery. After recovery, fluorescein permeability was assessed as described above ( $n=10$ per test solution). For each sample and time point, 10 replicates were averaged.

Transepithelial electrical resistance. For assessments of transepithelial electrical resistance, initial resistance across stratified cultures was measured before treatment with test solutions using a volt-ohm meter (World Precision Instruments, Inc., Sarasota, FL). After incubation with test formulations and Triton X-100 insult, inserts and wells were washed with HBSS Complete and percent electrical resistance was measured ( $n=4-5$ per test solution). Inserts and wells were replenished with the stratification medium $(0.5$ and $1.5 \mathrm{~mL}$, respectively), and cells were incubated at $37^{\circ} \mathrm{C}$ for $4 \mathrm{~h}$ of recovery before electrical resistance was measured again. The resistance of treated cells was corrected against resistance of a blank well; percent resistance was calculated as (post-treatment resistance $\div$ pretreatment resistance $) \times 100$.

Cell viability. Cell viability was assessed immediately after the Triton X-100 insult. Cells were rinsed with HBSS Complete and subjected to the Live/Dead ${ }^{\circledR}$ Viability/ Cytotoxicity assay (Life Technologies) according to the manufacturer's instructions. Representative images for 3 wells per test formulation were collected using fluorescence microscopy.

\section{Surface lubrication}

To assess surface lubrication, friction was measured during simulated blinking in pericardium-pericardium tribological experiments adapted from previously published methods. ${ }^{12,13}$ Bovine pericardium was soaked for $\geq 15 \mathrm{~min}$ 
in preservative-free saline (Unisol; Alcon Laboratories, Inc., Fort Worth, TX), rinsed with tap water, and soaked in saline until testing was performed. Blinking was simulated with 2 pieces of pericardium ( $n=3$ per test solution) on a reciprocating stage at a rate of 30 cycles/min with a velocity of $2.5 \mathrm{~cm} / \mathrm{s}$ with a normal tissue-to-tissue pressure of $8 \mathrm{kPa}$. Baseline friction was measured before application of test solutions (pretreatment). Next, $50 \mu \mathrm{L}$ of test formulations was added, and friction was measured after 1 and 2 min of treatment. To evaluate sustained lubricity, test formulations were removed, tissues were blotted, and $50 \mu \mathrm{L}$ of saline was added before friction was measured again (post-treatment 1). Blotting, addition of saline, and measurement of friction at $t=1 \mathrm{~min}$ were performed an additional 5 times for a total of 6 post-treatment measurements, each time measuring after $1 \mathrm{~min}$.

\section{Data analysis and statistics}

For each assay yielding numeric data, descriptive means and SDs were calculated. Data were analyzed by one-way analysis of variance, with $P<0.05$ considered significant. Pairwise comparisons were assessed using two-sided $t$-tests with unequal variance assumed.

\section{Results}

\section{Cell hydration and surface retention}

Hydration protection against desiccation was significantly greater with HA/HPG compared with media controls, HPG alone, or HA alone $(P<0.001$; Fig. 1A); protection with HPG was significantly greater compared with HA $(P=0.016)$. After desiccation, mean \pm SD cell protection was $0.4 \% \pm 1.4 \%$ in media controls, $36.5 \% \pm 14.2 \%$ with HPG pretreatment, $25.0 \% \pm 10.4 \%$ with HA pretreatment, and $53.6 \% \pm 10.7 \%$ with $\mathrm{HA} / \mathrm{HPG}$ pretreatment. Cell protection by surface retention of test formulations after removal and rinsing was also significantly greater with $\mathrm{HA} / \mathrm{HPG}$ compared with media controls, HPG, and HA $(P<0.001)$ and with HPG compared with HA $(P=0.01$; Fig. $1 \mathrm{~B})$. Mean \pm SD cell viability was $2.0 \% \pm 5.5 \%$ in media controls and $29.8 \% \pm 6.8 \%, 21.5 \% \pm$ $5.6 \%$, and $44.4 \% \pm 12.5 \%$ in samples pretreated with HPG, $\mathrm{HA}$, and $\mathrm{HA} / \mathrm{HPG}$, respectively.

\section{Cell and cell barrier protection}

Sodium fluorescein permeability. Samples pretreated with HA or HA/HPG demonstrated significantly less fluorescein permeability immediately after the Triton X-100 insult compared with media controls $(P<0.001$; Fig. 2A). Permeability was also significantly lower with HA/HPG compared with HA alone $(P=0.01)$. Mean \pm SD fluorescence values indicating the degree of permeability were 4.0 \pm 0.4 RFUs in media controls, 3.4 \pm 0.4 RFUs with HPG, $3.7 \pm 0.4$ RFUs with HA, and 3.0 \pm 0.3 RFUs with HA/HPG. A similar trend was observed after $4 \mathrm{~h}$ of recovery postinsult; significantly less permeability was evident with HA and HA/HPG compared with media controls $(P=0.02$ and $P<0.001$, respectively) and with $\mathrm{HA} / \mathrm{HPG}$ compared with HA $(P=0.01$; Fig. 2B). Fluorescence values were $4.7 \pm 0.9$ RFUs in media controls and were $3.9 \pm 0.5,4.3 \pm 0.5$, and $3.2 \pm 0.4$ RFUs with HPG, HA, and HA/HPG pretreatment, respectively.
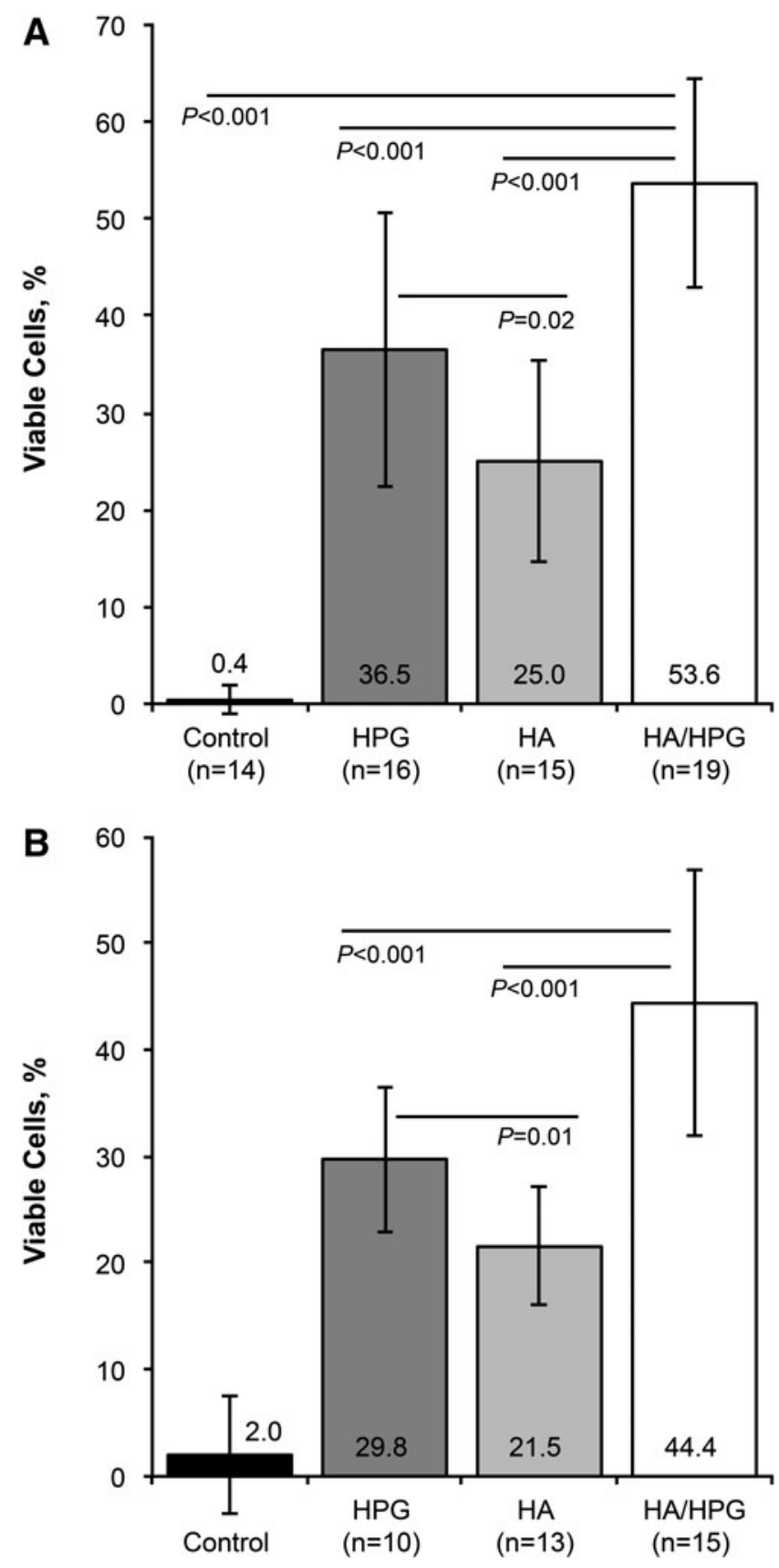

FIG. 1. Hydration protection against desiccation (A) after pretreatment with test solutions and (B) after test solutions were rinsed from the cell surface. HA, hyaluronic acid; HA/HPG, hyaluronic acid + hydroxypropyl guar dual-polymer formulation; HPG, hydroxypropyl guar.

Transepithelial electrical resistance. Immediately after the Triton X-100 insult, mean \pm SD transepithelial electrical resistance, relative to pretreatment resistance, was approximately $80 \% \pm 8 \%$ in media controls, HPG-treated samples, and HA-treated samples, and $93 \% \pm 11 \%$ in samples pretreated with HA/HPG (Fig. 3A). There were no significant differences between treatments. However, after $4 \mathrm{~h}$ of postinsult recovery, resistance was significantly greater with HA/HPG compared with media controls, HPG-treated samples, and HA-treated samples $(P<0.001$; Fig. 3B). Resistance was $75 \% \pm 10 \%$ in media controls, $79 \% \pm 8 \%$ with $\mathrm{HPG}$, $81 \% \pm 7 \%$ with $\mathrm{HA}$, and $111 \% \pm 6 \%$ with $\mathrm{HA} / \mathrm{HPG}$. In the 

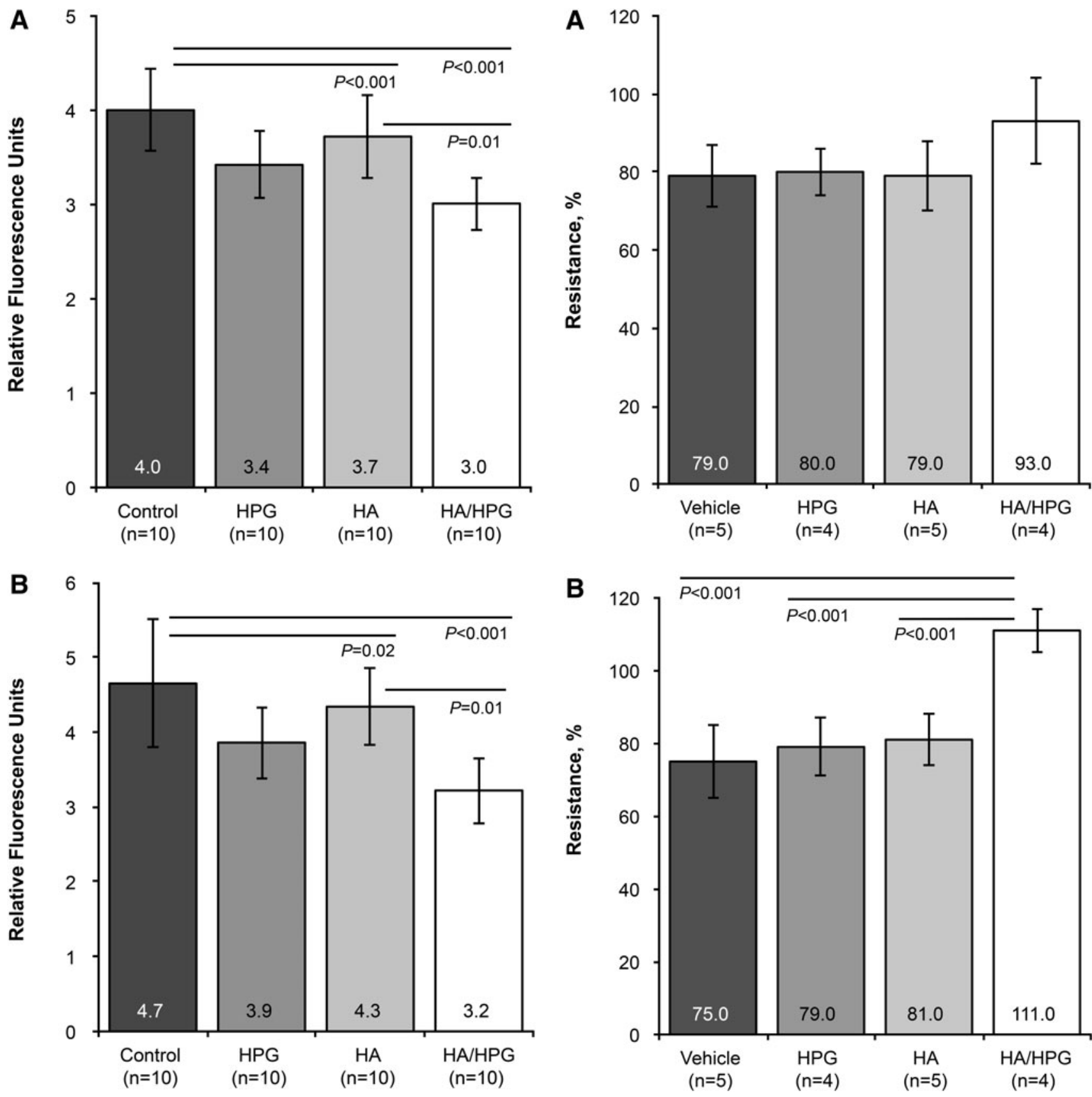

FIG. 2. Fluorescein permeability of pretreated human corneal epithelial cells (A) immediately after surfactant exposure and (B) after $4 \mathrm{~h}$ of recovery postinsult.

HA/HPG-treated cells, this represented an approximately $20 \%$ greater resistance after $4 \mathrm{~h}$ of recovery compared with immediately after the Triton X-100 insult.

Cell viability. After the Triton X-100 insult, markedly more viable cells were observed with HA/HPG compared with media controls, HPG alone, and HA alone (Fig. 4). Cell viability was similar between media controls, HPG-treated samples, and HA-treated samples.

\section{Surface lubrication}

Hydrodynamic friction was similar among pericardial tissue samples before application of test solutions. At $1 \mathrm{~min}$

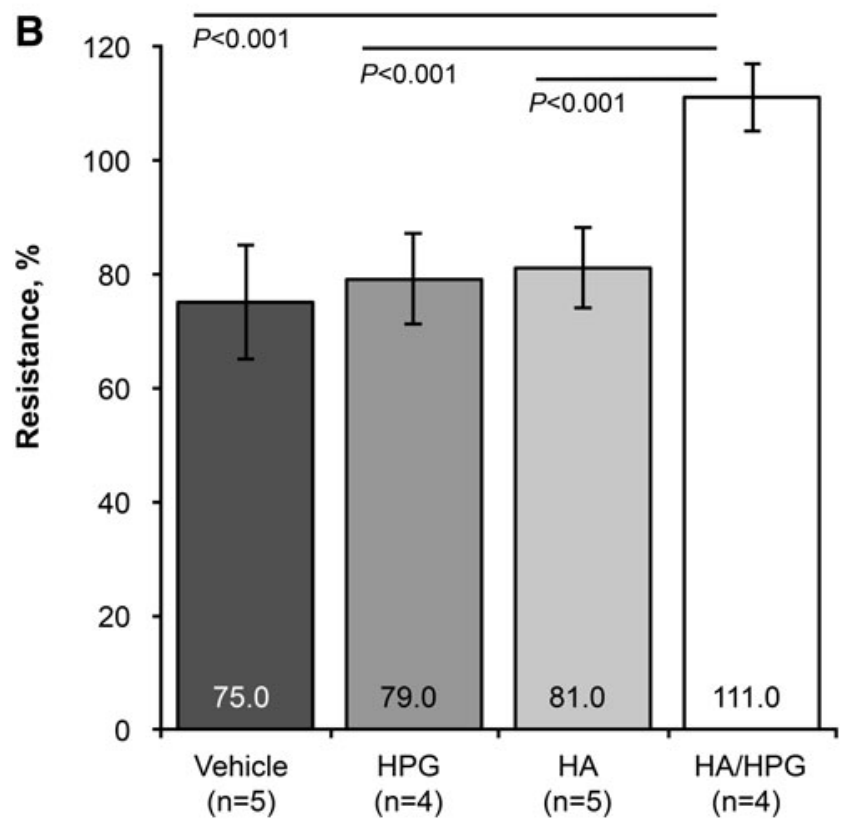

FIG. 3. Transepithelial electrical resistance of pretreated human corneal epithelial cells (A) immediately after surfactant exposure and (B) after $4 \mathrm{~h}$ of recovery postinsult.

after solution application, friction was significantly reduced in tissues treated with HA/HPG, HPG, or HA compared with saline ( $P=0.007, P=0.01$, and $P=0.01$, respectively; Fig. 5). Significantly less friction was also observed with HA/HPG compared with HA $(P=0.02)$. The mean \pm SD coefficient of friction was $0.53 \pm 0.07$ with saline, $0.07 \pm 0.01$ with $\mathrm{HA} / \mathrm{HPG}, 0.07 \pm 0.01$ with $\mathrm{HPG}$, and $0.53 \pm 0.7$ with HA. Similar results were observed at 2 min after solution application. After solutions were blotted and saline was added to tissues, friction values remained significantly lower at posttreatment measurement 1 in the HA/HPG-treated tissues compared with HA-treated tissues $(0.08 \pm 0.04$ vs. $0.45 \pm$ $0.04, P<0.001)$. After the blotting and saline application 


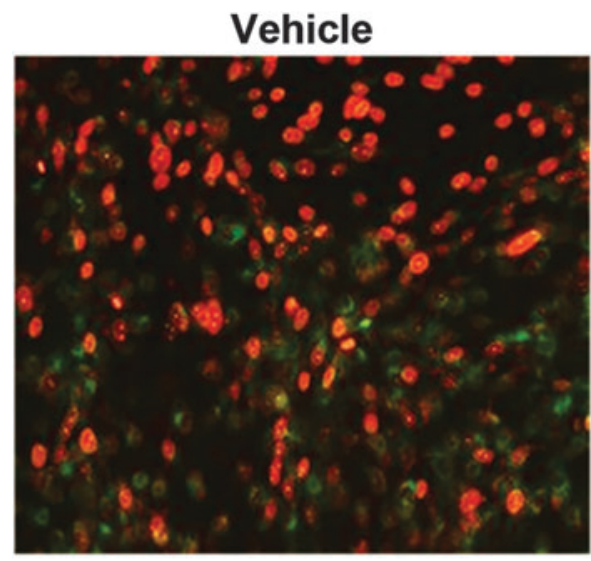

HA

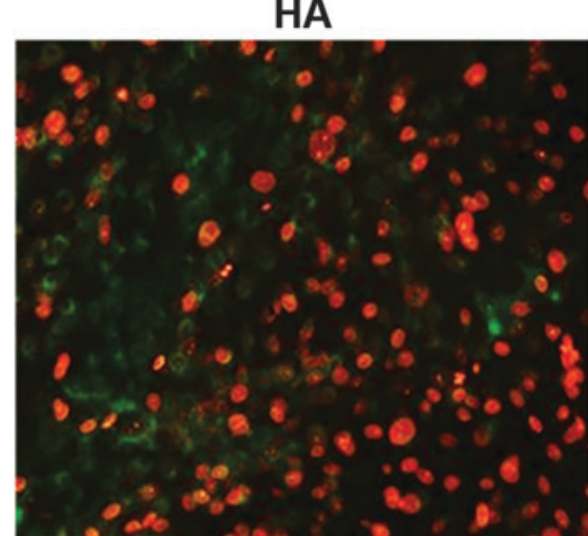

HPG

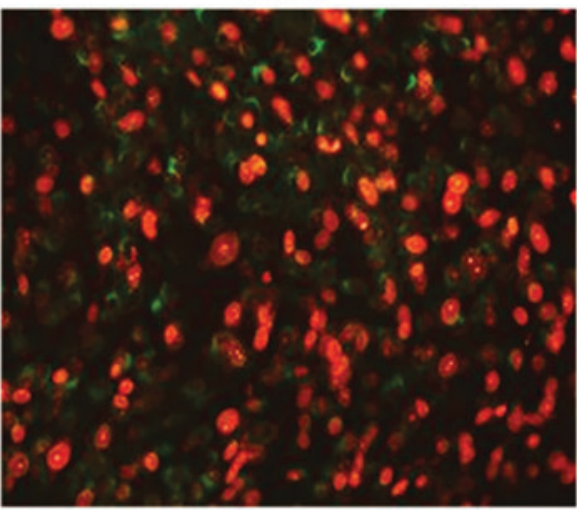

HA/HPG

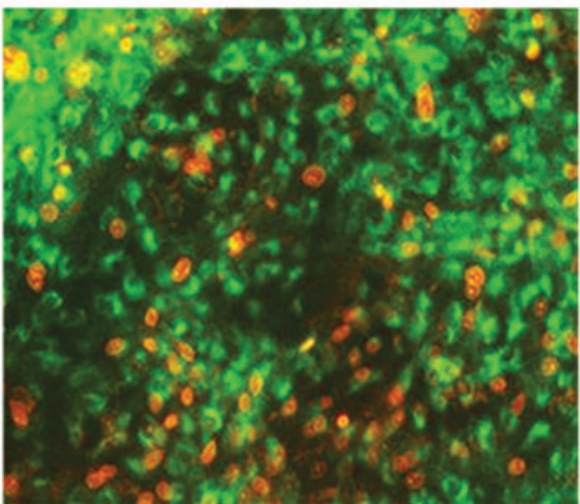

FIG. 4. Viability of human corneal epithelial cells after surfactant exposure. Green, live cells; red, dead cells. procedure was repeated (i.e., post-treatment measurement 2), the coefficient of friction was similar between saline control and HA-pretreated tissues. Friction values remained numerically lower in HA/HPG-pretreated tissues compared with HA-treated tissues in post-treatment measurements 2 through 6. HPG-treated tissues demonstrated nonsignificantly lower friction values in several post-treatment measurements compared with other treatments.

\section{Discussion}

Management of dry eye relies largely on the use of artificial tears. Formulations with prolonged hydration and lubrication effects may reduce ocular surface damage associated with tissue desiccation and increased friction in chronic dry eye. Using in vitro models of the corneal epithelium, we compared HA/HPG versus HPG or HA alone in hydration and surface retention, cell and cell barrier protection, and surface lubricity. Compared with HPG or HA, HA/HPG conferred significantly greater cell protection against desiccation immediately after treatment (i.e., hydration) and after the formulation was rinsed away (i.e., retention of effect). Additionally, desiccation protection was significantly greater with HPG compared with HA. Cell barrier protection from a surfactant insult was significantly greater with HA/HPG compared with controls and HA, and

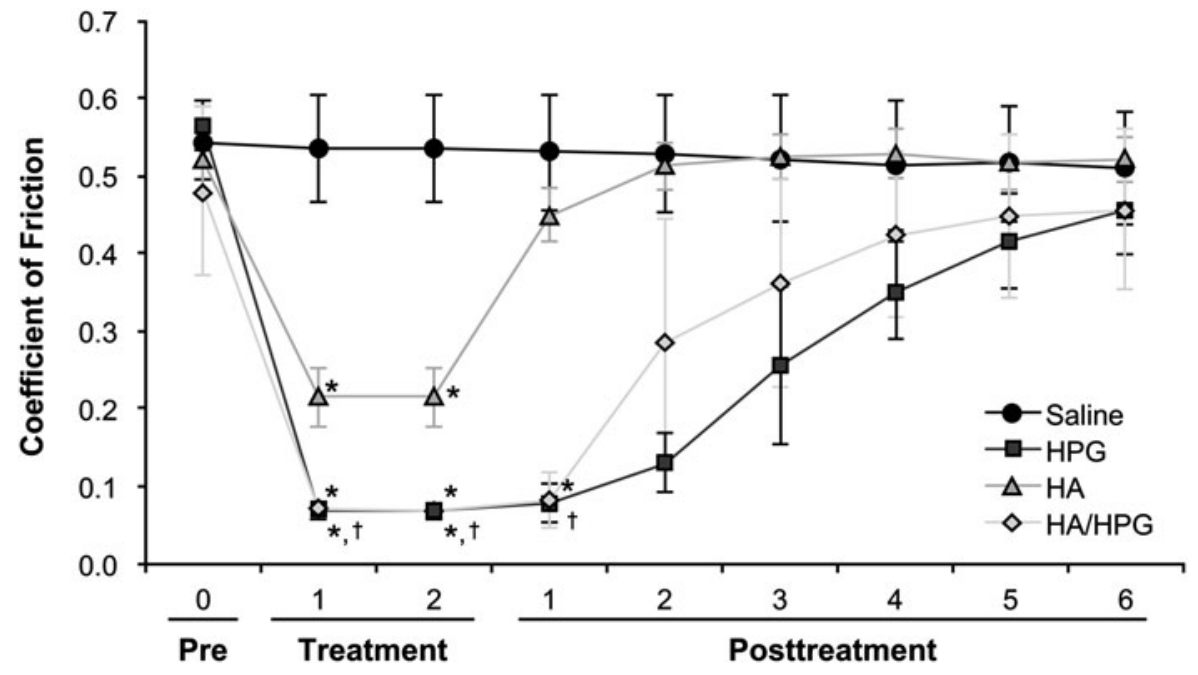

FIG. 5. Surface friction of bovine pericardial tissue before and after treatment with test solutions. pre, pretreatment. $* P<0.05$ versus saline; ${ }^{\dagger} P<0.05$ versus HA. 
cell protection was markedly improved with HA/HPG compared with all other formulations. In experiments designed to simulate blinking, HA/HPG and HA significantly reduced surface friction compared with saline; there was also significantly less tissue friction with HA/HPG compared with HA immediately after treatment and after the formulations were removed and replaced with saline.

The results of this study build on previous reports of the effects of artificial tears containing HPG or HA. Rabbit corneas and cultured corneal cells treated with the HPG formulation demonstrated significantly greater cell viability and better cell barrier function compared with a similar formulation without HPG. ${ }^{14}$ A randomized, double-masked crossover study of patients with dry eye demonstrated that an artificial tear containing HPG significantly prolonged tear film break-up time compared with eye drops without HPG for up to $60 \mathrm{~min}$ after instillation, suggesting that HPG promotes longer-lasting hydration protection from desiccation. ${ }^{15}$ Eye drops containing HA were also shown to improve corneal epithelial cell vitality and barrier integrity in patients with dry eye. ${ }^{16,17}$ Additionally, eye drops containing HA may protect the ocular surface from damage in patients with dry eye. ${ }^{7}$

In the current study, an eye drop formulation containing HA/HPG significantly improved hydration protection and surface retention compared with HPG or HA alone, suggesting that eye drops combining HPG and HA may offer increased and sustained hydration in patients with dry eye. Cell barrier function following treatment with the dualpolymer formulation was also significantly better compared with HA and numerically better than HPG, and epithelial cell viability was considerably greater with HA/HPG compared with either polymer alone, indicating an additive effect of HPG and HA in epithelial cell and cell barrier protection. The HA/HPG formulation also conferred significantly greater and more prolonged tissue lubricity compared with HA. This finding further suggests that HA/HPG may reduce ocular surface damage in chronic dry eye by reducing surface friction.

A potential limitation of this study was the use of in vitro preclinical models, which limits extrapolation of study results to clinical applications. Physical characteristics (e.g., viscosity, mucoadhesive properties) may have differed among the test solutions, which could have influenced hydration, surface retention, and lubrication.

In conclusion, the dual-polymer $\mathrm{HA} / \mathrm{HPG}$ formulation provided an effective moisture layer that resulted in significantly greater cell viability after desiccation than either polymer alone, and protection from desiccation was evident even after test solutions were rinsed away. Cell and cell barrier protection from surfactant insult was also significantly greater with HA/HPG. The dual-polymer formulation significantly reduced hydrodynamic surface friction to a greater extent than HA alone, suggesting increased tissue hydration and lubricity. HA/HPG may protect the ocular surface from damage associated with dry eye.

\section{Acknowledgments}

This study was funded by Alcon Research, Ltd. The authors thank Dr. John Ubels (Department of Biology, Calvin College, Grand Rapids, MI) for assistance with cell and cell barrier protection experiments and Drs. Robert Baier and
Anne Meyer (School of Dental Medicine, SUNY Buffalo, Buffalo, NY) for assistance with surface lubrication experiments. Medical writing assistance was provided by Heather D. Starkey, $\mathrm{PhD}$, of Complete Healthcare Communications, Inc. (Chadds Ford, PA) and was funded by Alcon. The authors are Alcon employees.

\section{Author Disclosure Statement}

Drs. Rangarajan, Kraybill, Ogundele, and Ketelson are employees of Alcon Research, Ltd., Fort Worth, TX. No other competing financial interests exist.

\section{References}

1. Research in dry eye: report of the Research Subcommittee of the International Dry Eye WorkShop (2007). Ocul. Surf. 5:179-193, 2007.

2. The definition and classification of dry eye disease: report of the Definition and Classification Subcommittee of the International Dry Eye WorkShop (2007). Ocul. Surf. 5:7592, 2007.

3. Geerling, G., Tauber, J., Baudouin, C., et al. The international workshop on meibomian gland dysfunction: report of the subcommittee on management and treatment of meibomian gland dysfunction. Invest. Ophthalmol. Vis. Sci. 52:2050-2064, 2011.

4. Lee, S.Y., and Tong, L. Lipid-containing lubricants for dry eye: a systematic review. Optom. Vis. Sci. 89:1654-1661, 2012.

5. Petricek, I., Berta, A., Higazy, M.T., Nemeth, J., and Prost, M.E. Hydroxypropyl-guar gellable lubricant eye drops for dry eye treatment. Expert Opin. Pharmacother. 9:14311436, 2008.

6. Paugh, J.R., Nguyen, A.L., Ketelson, H.A., Christensen, M.T., and Meadows, D.L. Precorneal residence time of artificial tears measured in dry eye subjects. Optom. Vis. Sci. 85:725-731, 2008.

7. Aragona, P., Papa, V., Micali, A., Santocono, M., and Milazzo, G. Long term treatment with sodium hyaluronatecontaining artificial tears reduces ocular surface damage in patients with dry eye. Br. J. Ophthalmol. 86:181-184, 2002.

8. Johnson, M.E., Murphy, P.J., and Boulton, M. Effectiveness of sodium hyaluronate eyedrops in the treatment of dry eye. Graefes Arch. Clin. Exp. Ophthalmol. 244:109-112, 2006.

9. Wang, T.J., Wang, I.J., Ho, J.D., et al. Comparison of the clinical effects of carbomer-based lipid-containing gel and hydroxypropyl-guar gel artificial tear formulations in patients with dry eye syndrome: a 4-week, prospective, open-label, randomized, parallel-group, noninferiority study. Clin. Ther. 32:44-52, 2010.

10. Christensen, M.T., Cohen, S., Rinehart, J., et al. Clinical evaluation of an HP-guar gellable lubricant eye drop for the relief of dryness of the eye. Curr. Eye Res. 28:55-62, 2004.

11. Jacobi, C., Kruse, F.E., and Cursiefen, C. Prospective, randomized, controlled comparison of SYSTANE UD eye drops versus VISINE INTENSIV 1\% EDO eye drops for the treatment of moderate dry eye. J. Ocul. Pharmacol. Ther. 28:598-603, 2012.

12. Meyer, A.E., Baier, R.E., Chen, H., and Chowhan, M. Tissue-on-tissue testing of dry eye formulations for reduction of bioadhesion. J. Adhes. 82:607-627, 2006.

13. Meyer, A.E., Baier, R.E., Chen, H., and Chowhan, M. Differential tissue-on-tissue lubrication by ophthalmic formulations. J. Biomed. Mater. Res. B Appl. Biomater. 82:74-88, 2007.

14. Ubels, J.L., Clousing, D.P., Van Haitsma, T.A., et al. Preclinical investigation of the efficacy of an artificial tear 
solution containing hydroxypropyl-guar as a gelling agent. Curr. Eye Res. 28:437-444, 2004.

15. Ousler, G.W., Michaelson, C., and Christensen, M.T. An evaluation of tear film breakup time extension and ocular protection index scores among three marketed lubricant eye drops. Cornea. 26:949-952, 2007.

16. Troiano, P., and Monaco, G. Effect of hypotonic $0.4 \%$ hyaluronic acid drops in dry eye patients: a cross-over study. Cornea. 27:1126-1130, 2008.

17. Yokoi, N., Komuro, A., Nishida, K., and Kinoshita, S. Effectiveness of hyaluronan on corneal epithelial barrier function in dry eye. Br. J. Ophthalmol. 81:533-536, 1997.
Received: December 17, 2014

Accepted: April 15, 2015

Address correspondence to: Dr. Rekha Rangarajan Alcon Research, Ltd. 6201 South Freeway Fort Worth, TX 76134

E-mail: rekha.rangarajan@alcon.com 